\title{
Association between Sex Differences and the Pharmacokinetics of Repaglinide among a Malaysian Population
}

\author{
Ruzilawati Abu Bakar $^{1 *}$, Mohd Suhaimi Ab Wahab, Imran Ahmad², Gan Siew Hua ${ }^{3}$ \\ ${ }^{1}$ Department of Pharmacology, Universiti Sains Malaysia, Kota Bharu, Malaysia; ${ }^{2}$ Department of Family Medicine, Universiti Sains \\ Malaysia, Kota Bharu, Malaysia; ${ }^{3}$ Human Genome Centre, School of Medical Sciences, Universiti Sains Malaysia, Kota Bharu, Ma- \\ laysia. \\ Email: *tieimran@yahoo.com
}

Received April 28 ${ }^{\text {th }}$, 2011; revised May 20 ${ }^{\text {th }}$, 2011; accepted June 25 ${ }^{\text {th }}, 2011$.

\begin{abstract}
This study was conducted to evaluate the effect of sex differences on the pharmacokinetics of repaglinide in healthy subjects. One hundred twenty one healthy volunteers (61 male and 60 female; aged 18 - 50 years) were included in the study. Subjects were administered a single 4-mg repaglinide oral dose. Blood samples were taken at 0, 30, 60, 120, 180 and $240 \mathrm{~min}$. Serum repaglinide levels were determined by a high-performance liquid chromatography (HPLC) method. Subjects were also genotyped by polymerase chain reactions-restriction fragment length polymorphisms (PCR-RFLP) for CYP3A4*4, *5 and *18 alleles and by an allele-specific multiplex PCR for CYP2C8*2, *3, *4 and *5 alleles. The pharmacokinetics of repaglinide were comparable between male and female subjects. The mean clearance $(C L)$ of repaglinide was $16.0 \%$ lower $(p=0.03$ ), the mean area under the serum concentration-time curve (AUC) was $12.8 \%$ higher $(p=0.04)$ and the peak serum concentration $\left(C_{\max }\right)$ was $13.2 \%$ higher $(p=0.03)$ in females compared to male subjects. The mean rate of elimination (kel) and mean CL of repaglinide were $47.67 \%(p=0.03)$ higher and $29.25 \%(p$ $=0.03)$ higher, respectively, in male subjects having CYP2C $8 * 5$ allele compared to female subjects. We also found that the mean half-life $\left(t_{1 / 2}\right)$ of repaglinide was $42.43 \%$ higher $(p=0.03)$, and the mean AUC was $35.83 \%$ higher $(p=0.03)$ in female subjects when compared to the male subjects having CYP2C $8 * 5$ allele. Sex differences significantly influence the pharmacokinetics of repaglinide.
\end{abstract}

Keywords: Sex Differences, CYP2C8, CYP3A4, Polymorphisms, Repaglinide

\section{Introduction}

Repaglinide was the first meglitinide analogue to become available. It is used in type 2 diabetic patients to normalise postprandial hyperglycaemia [1,2]. Like the sulfonylureas, repaglinide reduced blood glucose by stimulating insulin release from pancreatic $\beta$-cells [3]. It has a fast onset and short duration of action. Repaglinide is rapidly absorbed from the gastrointestinal tract after oral administration and eliminated in the bile. Only a very small fraction of the administered dose is excreted through the urine. It differs from other antidiabetic agents in its structure, binding profile, duration of action and mode of excretion [3]. Cytochrome P4502C8 (CYP2C8) and cytochrome P4503A4 (CYP3A4) are the principal enzymes that participate in its oxidative biotransformation [4].

CYP2C8 is the major human hepatic P450, constitut- ing about $12 \%$ of total microsomal CYP content in the liver [5] in which it conducts oxidative metabolism of at least $5 \%$ of drugs cleared by phase I metabolism. Drugs for which CYP2C8 contributes significantly to their biotransformation include the anticancer drug paclitaxel [6], the antidiabetic drugs rosiglitazone and troglitazone [7] and repaglinide [4], the antimalarial amodiaquine [6] and the hydroxymethylglutaryl co-enzyme A reductase inhibitors such as cerivastatin and fluvastatin [8].

CYP3A4 is involved in the metabolism of more than $60 \%$ of all drugs used in humans [5]. It is found in human livers, gastrointestinal tracts, kidneys, lungs, brains, endotheliums, placentas, lymphocytes and intestines [9]. It plays important roles in the metabolism of drugs used in humans including antidiabetics, antiarrhythmics, antihistamines, synthetic oestrogens, cancer chemotherapeutic drugs, human immunodeficiency virus protease in- 
hibitors, calcium channel antagonists, immunosuppressants and cholesterol-lowering drugs [10].

Numerous studies have examined the influence of sex differences on drug metabolism. Physiological factors such as differences in body weight and composition, metabolizing enzymes or hormone concentrations may differentially affect the pharmacokinetics and pharmacodynamics of many drugs between women and men [11]. Ignoring these sex differences during drug development may lead to side-effects or toxicity as well as inadequate response during drug treatment due to these differences in drug metabolism [11].

Several investigators also have attempted to determine potential sex differences in the metabolic activity of cytochrome P450 (CYP) enzymes including CYP3A and CYP2C. Some studies suggest higher CYP enzymes activities in women than men [12], there are also reports of no sex differences [13] or even lower in activities in women [14]. Thus, these findings have been largely inconsistent or inconclusive.

This study was designed to investigate the influence of sex differences on the pharmacokinetics of repaglinide. The secondary objective was to investigate whether sex differences exist in CYP3A4 and CYP2C8 activities by use of population pharmacokinetic modelling methods.

\section{Materials and Methods}

The study was conducted following approval by the Research and Ethics Committee, School of Medical Sciences, Universiti Sains Malaysia. All the subjects gave their written informed consent prior to study enrolment.

One hundred twenty one healthy volunteers were recruited, including 61 men and 60 women. All subjects aged 18 to 50 years with a normal body mass index (BMI). These volunteers were students and staff of Universiti Sains Malaysia, Health Campus, Kelantan, Malaysia. They were ascertained to be healthy by a medical history, physical examination and routine laboratory tests.

Subjects were asked to fast overnight before the study. On the day of repaglinide administration, $5 \mathrm{ml}$ of blood were collected in plain vacutainer tubes to determine repaglinide's concentration at $0 \mathrm{~min}$ (baseline). Subjects then administered a single 4-mg repaglinide [Novo Nordisk, Denmark] oral dose with $100 \mathrm{ml}$ of water. On each study day subjects were allowed to have a light breakfast, precisely $10 \mathrm{~min}$ after repaglinide administration. The breakfast was eaten within $10 \mathrm{~min}$. The breakfast consisted of one sandwich (two pieces of bread with eggs, tomato and margarine) and contained approximately $1550 \mathrm{~kJ}$ energy, $70 \mathrm{~g}$ carbohydrates, 8 g protein and $6 \mathrm{~g}$ fat. Blood samples $(5 \mathrm{~mL}$ into vacutainer for pharmacokinetic study) were drawn from a cannulated forearm vein at five designated times: $30,60,120,180$ and $240 \mathrm{~min}$. Serum were separated within $30 \mathrm{~min}$ after blood sampling.

During the day of repaglinide administration, the subjects were under direct medical supervision and blood glucose levels were monitored throughout the day. Additional glucose solution for intravenous use and glucagons for intramuscular use were available in case of severe hypoglycaemia but they were not needed.

The reversed-phase high performance liquid chromatographic (HPLC) methods described by Ruzilawati et al. [15] were used to measure serum repaglinide concentrations. In brief, samples were processed after addition of the internal standard (indomethacin, Sigma-Aldrich, St. Louis, MO, USA). A calibration curve was analysed in the concentration range of $20-200 \mathrm{ng} / \mathrm{ml}$. Samples were extracted with ethyl acetate and injected into the chromatographic system composed of an automatic sampler (Waters, Mildford, MA, USA). Reversed-phase chromatographic separation was achieved on Purospher ${ }^{\circledR}$ STAR C-18 analytical column $(4.8 \mathrm{~mm} \times 150 \mathrm{~mm}$; $5 \mu \mathrm{m}$ particle size). The mobile phase consisted of $60: 40 \mathrm{v} / \mathrm{v}$ acetonitrile - ammonium formate $(\mathrm{pH} 2.7 ; 0.01 \mathrm{M})$ and was run at $1 \mathrm{ml} / \mathrm{min}$. The retention times of indomethacin and repaglinide were approximately 5.3 and $6.2 \mathrm{~min}$, respectively.

For genetic analysis, a $5 \mathrm{~mL}$ ethylenediaminetetraacetic acid (EDTA) blood sample was drawn from each subject and stored at $-20^{\circ} \mathrm{C}$ until deoxyribonucleic acid (DNA) extraction. DNA was extracted with standard methods (QIAamp DNA Blood Mini Kit, Qiagen, Hilden, Germany). All subjects were genotyped for CYP3A4*4, $* 5$ and $* 18$ alleles by the polymerase chain reaction- restriction fragment length polymorphism (PCR-RFLP) method as described by Ruzilawati et al. [16]. Subjects were also genotyped for $\mathrm{CYP} 2 \mathrm{C} 8 * 2$, *3 and *4 alleles. The method of allele-specific PCR based on a previously published protocol described by Muthiah et al. [17] was used.

The population pharmacokinetic parameters of repaglinide was characterized by the Nonparametric Adaptive Grid (NPAG) programme, a module of USC*PACK ${ }^{\circledR}$ (version 12.0) [18].

Mann-Whitney tests were used to compare the effect of sex on repaglinide pharmacokinetic parameters using the SPSS package (ver. 12, SPSS, Chicago, IL). Data were presented as mean $\pm \mathrm{SD}$. A $p$ value of $<0.05$ was considered to be statistically significant.

\section{Results}

One hundred and twenty one subjects completed the study. Demographic data for the 121 subjects are displayed in Table 1. The comparison between healthy male 
and female subjects' repaglinide pharmacokinetic is shown in Tables 2-4 summarize CYP3A4 and CYP2C8 genetic polymorphisms by sex in our subjects, respectively. The comparison between the pharmacokinetic parameters of repaglinide after a single oral dose of $4 \mathrm{mg}$ in male and female subjects having CYP2C $8 * 5$ allele is shown in Table 5.

\section{Discussion}

Gender may be an important variable in the processes of absorption, distribution, metabolism, and excretion. There are several factors that may contribute to sex-related differences in pharmacokinetics. These factors are gastric acid secretion, gastrointestinal blood flow, proportions of muscular and adipose tissue, amount of drug binding

Table 1. Demographics of 121 subjects.

\begin{tabular}{lcc}
\hline & Male $(\mathbf{n}=\mathbf{6 1})$ & Female $(\mathbf{n}=\mathbf{6 0})$ \\
\hline Age (year) & $29.54 \pm 7.37$ & $25.00 \pm 5.76$ \\
Body weight $(\mathbf{k g})$ & $62.06 \pm 7.20$ & $54.19 \pm 7.59$ \\
Height $(\mathbf{m})$ & $166.92 \pm 5.72$ & $157.23 \pm 7.27$ \\
BMI $\left(\mathbf{k g} / \mathbf{m}^{2}\right)$ & $22.17 \pm 1.92$ & $21.73 \pm 2.00$ \\
\hline
\end{tabular}

Table 2. Mean \pm SD pharmacokinetic parameters of repaglinide after a single dose of $\mathbf{4} \mathbf{~ m g}$ in male and female subjects.

\begin{tabular}{lccc}
\hline \multicolumn{1}{c}{ Variable } & Male $(\mathbf{n}=\mathbf{6 1})$ & Female $(\mathbf{n}=\mathbf{6 0})$ & $\boldsymbol{p}$ \\
\hline Mean Vd (L) & $23.48 \pm 9.05$ & $22.21 \pm 9.64$ & $0.31(\mathrm{NS})$ \\
Mean kel $\left(\mathrm{h}^{-1}\right)$ & $0.58 \pm 0.24$ & $0.57 \pm 0.29$ & $0.34(\mathrm{NS})$ \\
Mean CL (L/h) & $12.91 \pm 4.16$ & $10.91 \pm 3.51$ & 0.03 \\
Mean $_{1 / 2}(\mathrm{~h})$ & $1.37 \pm 0.49$ & $1.47 \pm 0.59$ & $0.34(\mathrm{NS})$ \\
Mean $_{\max }(\mathrm{ng} / \mathrm{ml})$ & $79.45 \pm 28.28$ & $89.95 \pm 26.53$ & 0.03 \\
Mean $\mathrm{t}_{\max }(\mathrm{h})$ & $0.65 \pm 0.39$ & $0.58 \pm 0.37$ & $0.26(\mathrm{NS})$ \\
Mean AUC (ng/ml per h) & $324.50 \pm 109.82$ & $366.03 \pm 117.86$ & 0.04 \\
\hline
\end{tabular}

NS: not significant.

Table 3. CYP3A4 genetic polymorphisms by sex in healthy subjects.

\begin{tabular}{ccc}
\hline Genotypes & Male n (\%) & Female n (\%) \\
\hline CYP3A4*1 & $56(91.8 \%)$ & $60(100 \%)$ \\
CYP3A4*4 & 0 & 0 \\
CYP3A4*5 & 0 & 0 \\
CYP3A4*18 & $5(8.2 \%)$ & 0 \\
TOTAL & $61(100 \%)$ & $60(100 \%)$ \\
\hline
\end{tabular}

Table 4. CYP2C8 genetic polymorphisms by sex in healthy subjects.

\begin{tabular}{ccc}
\hline Genotypes & Male n (\%) & Female n (\%) \\
\hline CYP2C8*1 & $54(88.54 \%)$ & $54(90 \%)$ \\
CYP2C8*2 & $1(1.63 \%)$ & 0 \\
CYP2C8*3 & $1(1.63 \%)$ & 0 \\
CYP2C8*4 & 0 & 0 \\
CYP2C8*5 & $5(8.2 \%)$ & $6(10 \%)$ \\
TOTAL & $61(100 \%)$ & $60(100 \%)$ \\
\hline
\end{tabular}

Table 5. Mean \pm SD pharmacokinetic parameters of repaglinide after a single oral dose of $4 \mathbf{~ m g}$ in male and female subjects having CYP2C8*5 allele.

\begin{tabular}{lccc}
\hline \multicolumn{1}{c}{ Variable } & Male $(\mathbf{n}=5)$ & Female $(\mathbf{n}=5)$ & $\boldsymbol{p}$ \\
\hline Mean Vd (L) & $24.34 \pm 10.08$ & $30.34 \pm 13.17$ & $0.35(\mathrm{NS})$ \\
Mean kel $\left(\mathrm{h}^{-1}\right)$ & $0.65 \pm 0.25$ & $0.34 \pm 0.96$ & 0.03 \\
Mean CL (L/h) & $13.91 \pm 1.84$ & $9.84 \pm 3.12$ & 0.03 \\
Mean $_{1 / 2}(\mathrm{~h})$ & $1.22 \pm 0.48$ & $2.12 \pm 0.48$ & 0.03 \\
Mean $_{\text {max }}(\mathrm{ng} / \mathrm{ml})$ & $69.28 \pm 23.5$ & $80.21 \pm 34.85$ & $0.92(\mathrm{NS})$ \\
Mean $\mathrm{t}_{\text {max }}(\mathrm{h})$ & $0.73 \pm 0.38$ & $0.52 \pm 0.27$ & $0.35(\mathrm{NS})$ \\
Mean AUC (ng/ml per h) & $269.12 \pm 31.10$ & $419.40 \pm 130.89$ & 0.03 \\
\hline
\end{tabular}

NS: not significant.

proteins, sex-specific cytochrome P450 isozymes, physiologic and hormonal changes during the menstrual cycle as well as renal blood flow [19].

However, there has been little published work evaluating potential sex differences in pharmacokinetics of repaglinide.

The present study indicates that sex difference is significantly influences the pharmacokinetics of repaglinide. We found that the mean clearance (CL) of repaglinide was $16.0 \%$ lower $(p=0.03)$, the mean area under the serum concentration-time curve (AUC) was $12.8 \%$ higher $(p=0.04)$ and the peak serum concentration $\left(C_{\max }\right)$ was $13.2 \%$ higher $(p=0.03)$ in female compared to male subjects.

Haidar et al. [20] reported that, on average, female patients had larger AUC for repaglinide when compared to male patients. A higher bioavailability (higher AUC values) has also been reported for females than males by Harris et al. [21]. Regarding pharmacokinetic parameters of drugs administered by the oral route, gastrointestinal motility has also been shown to be affected by sex hormones, which is slower in females than in males [22].

Repaglinide is metabolised by oxidation process. Clear- 
ances of drugs that are metabolised by conjugation or oxidation tend to be slower in women [23,24]. In general, clearance of some drugs also depends on the rate of blood flow into the eliminating organ. Women have a smaller liver and a lower liver blood flow. According to Meibohm et al. [19], women have an approximately $10 \%$ lower glomerular filtration rate than men when normalized for body surface area. This might explain the observed $16 \%$ lower repaglinide clearance in female subjects relative to male subjects.

No significant differences were seen in other pharmacokinetic parameters such as rate of elimination (kel), rate of absorbtion (ka), half-life $\left(\mathrm{t}_{1 / 2}\right)$, volume of distribution (Vd) and time to reach $\mathrm{C}_{\max }\left(\mathrm{t}_{\max }\right)$ between male and female subjects.

Drug concentrations are dependent on the volume of distribution (Vd). The Vd of a drug can affect the amount of drug that give their effects at the site of action. Body composition between women and men are different. This factor might affect the Vd of certain drugs. Women have a higher percentage of adipose tissue than do men. Therefore, as suggested by Greenblatt et al. [25], there should be a much larger Vd in women for lipophilic drugs. This can result in a prolonged half-life of those drugs. However, this did not occur in repaglinide's pharmacokinetics when we compared between males and females.

Differences in pharmacokinetic parameters between males and females could also be explained by differences in sex hormones and the menstrual cycle. However, in this study, the phase of the menstrual cycle was not considered upon enrolment. Therefore, a new study would be necessary to evaluate if menstrual cycle affects repaglinide's pharmacokinetics.

The allele frequencies of the CYP3A $4 * 4$ and $* 5$ alleles were $0 \%$ respectively for both male and female subjects (Table 3). All five subjects (8.2\%) with CYP3A4*18 mutations were found to be male (Table 4).

Although some studies suggested higher CYP3A4 activity in women [26], there are no reports of sex differences in CYP3A4's expression and function [27]. One study even reported a lower enzyme activity in women [14]. Some drugs that are substrates of CYP3A4 showed higher clearance rates in women than in men, even after correction for physiologic factors such as body weight [21]. Some evidence supports the hypothesis that either higher CYP3A4 protein expression in women or female sex steroid modulation of CYP3A4 function could contribute to higher CYP3A4-mediated clearance in women [28]. According to Chen et al. [26], women have more CYP3A4. In vitro studies conducted by Wolbold et al. [29] that examined human liver samples detected higher CYP3A4 expression levels in female liver samples. Ta- naka [30] also suggested that drugs that are metabolised by CYP3A4 frequently appear to be eliminated faster by women. To date, however, there are no reports on sex differences in CYP3A4 activity using repaglinide and our study is the first. We did not however find a significant correlation between repaglinide pharmacokinetics and the various genotype groups, perhaps due to the unequal distribution of sexes in the various groups. Furthermore, we were unable to correlate sex and the observed kel and CL values of repaglinide because all of our subjects with the CYP3A4*18 genotype were male.

For CYP2C8, both subjects with CYP2C8*2 and CYP2C8*3 were male subjects. There were five males $(8.20 \%)$ and six $(10.00 \%)$ female subjects are having CYP2C8*5 allele. In our study we found that the mean (SD) kel and mean (SD) CL of repaglinide were $47.67 \%$ $(p=0.03)$ higher and $29.25 \%(p=0.03)$ higher, respectively, in male subjects having CYP2C $8 * 5$ allele compared to female subjects (Table 5). We also found that the mean (SD) $\mathrm{t}_{1 / 2}$ of repaglinide was $42.43 \%$ higher $(p=$ 0.03 ), and the mean (SD) AUC was $35.83 \%$ higher ( $p=$ 0.03 ) in female subjects when compared to the male subjects having CYP2C $8 * 5$ allele. However, there was no statistically significant change in the mean (SD) Vd, $\mathrm{C}_{\max }$ or $\mathrm{t}_{\max }$ of repaglinide.

Potential sex differences in CYP isoenzymes are expected to be most appropriately characterized by quantifying the metabolism of probe drugs that are indicative of a specific CYP activity [31]. Sex differences in activity of the CYP enzymes will result in differences in $\mathrm{Cl}$. However there is no prior study on CYP2C8 activity in male and female subjects. There are still large gaps in our knowledge of sex differences in CYP2C8 activity and therefore, significantly more research is needed.

In conclusion, the current data suggest that the pharmacokinetic of repaglinide can be different between women and men. Based on these data, we conclude that gender significantly influences the pharmacokinetics of repaglinide.

\section{Acknowledgements}

This study was financially supported by Universiti Sains Malaysia IRPA grant (grant no. 305/PPSP/6112222) and Universiti Sains Malaysia short-term grant (grant no. 304/PPSP/6131450).

\section{REFERENCES}

[1] A. Dornhorst, "Insulinotropic Meglitinide Analogues," Lancet, Vol. 358, No. 9294, 2001, pp. 1709-1716. doi:10.1016/S0140-6736(01)06715-0

[2] V. Hatorp, "Clinical Pharmacokinetics and Pharmacodynamics of Repaglinide,” Clinical Pharmacokinetics, Vol. 41, No. 7, 2002, pp. 471-483. 
doi:10.2165/00003088-200241070-00002

[3] C. R. Culy and B. Jarvis, "Repaglinide: A Review of Its Therapeutic Use in Treatment of Type 2 Diabetes Mellitus,” Drugs, Vol. 61, No. 11, 2001, pp. 1625-1660. doi:10.2165/00003495-200161110-00008

[4] T. B. Bidstrup, I. Bjornsdottir, U. G. Sidelmann, M. S. Thamsen and K. T. Hansen, "CYP2C8 and CYP3A4 Are the Principal Enzymes Involved in the Human in Vitro Biotransformation of the Insulin Secretagogue Repaglinide," British Journal of Clinical Pharmacology, Vol. 56, No. 3, 2003, pp. 301-314. doi:10.1046/j.0306-5251.2003.01862.x

[5] S. Rendic and F. J. Carlo, "Human Cytochrome P450 Enzyme: A Status Report Summarizing Their Reaction, Substrates, Inducers and Inhibitors," Drug Metabolism Reviews, Vol. 29, No. 1-2, 1997, pp. 413-580. doi:10.3109/03602539709037591

[6] D. Dai, C. Darryl, D. C. Zeldin, J. A. Blasidell, B. Chanas, S. J. Coulter, et al., "Polymorphisms in Human CYP2C8 Decrease Metabolism of the Anticancer Drug Paclitaxel and Arachidonic Acid,” Pharmacogenetics, Vol. 11, No. 7, 2001, pp. 597-607. doi:10.1097/00008571-200110000-00006

[7] H. Yamazaki, A. Shibata, M. Suzuki, M. Nakajima, N. Shimada and F. P. Guengerich, "Oxidation of Troglitazone to a Quinine-Type Metabolite Catalyzed by Cytocrome P450 2C8 and P450 3A4 in Human Liver Microsomes," Drug Metabolism and Disposition, Vol. 27, No. 11, 1999, pp. 1260-1266.

[8] W. Muck, "Clinical Pharmacokinetics of Cerivastatin," Clinical Pharmacokinetics, Vol. 39, No. 2, 2000, pp. 99-116. doi:10.2165/00003088-200039020-00002

[9] T. Shimada, H. Yamazaki, M. Mimura, Y. Inui and F. P. Guengerich, "Interindividual Variations in Human Liver Cytochrome P450 Enzymes Involved in the Oxidation of Drugs, Carcinogens and Toxic Chemicals," Journal of Pharmacology and Experimental Therapeutics, Vol. 270, No. 1, 1994, pp. 414-423.

[10] P. B. Watkins, "Non-Invasive Tests of CYP3A4 Enzymes," Pharmacogenetics, Vol. 4, No. 4, 1994, pp. 171-184. doi:10.1097/00008571-199408000-00001

[11] J. Hamilton and B. Parry, "Sex-Related Differences in Clinical Drug Response: Implications for Women's Health," Journal of the American Medical Women's Association, Vol. 38, No. 5, 1983, pp. 126-132.

[12] G. C. Yee, T. P. Lennon and D. J. Gmur, “Age-Dependent Cyclosporine: Pharmacokinetics in Marrow Transplant Recipients," Clinical Pharmacology \& Therapeutics, Vol. 40, No. 4, 1986, pp. 438-443. doi:10.1038/clpt.1986.204

[13] D. J. Greenbalt, J. S. Harmatz and L. L. von Moltke, “Age and Gender Effects on the Pharmacokinetics and Pharmacodynamics of Triazolam, a Cytochrome P450 3A Substrate," Clinical Pharmacology \& Therapeutics, Vol. 76, No. 5, 2004, pp. 467-479. doi:10.1016/j.clpt.2004.07.009

[14] M. E. Krecic-Shepard, C. R. Barnas, J. Slimko and J. B. Schwartz, "Faster Clearance of Sustained Release Verapamil in Men versus Women: Continuing Observations on Sex-Specific Defferencesafter Oral Administration of Verapamil,” Clinical Pharmacology \& Therapeutics, Vol. 68, No. 3, 2000, pp. 286-292. doi: $10.1067 / \mathrm{mcp} .2000 .109356$

[15] A. B. Ruzilawati, A. W. Suhaimi, A. Imran, Z. Ismail and S. H. Gan, "Method Development and Validation of Repaglinide in Human Plasma by HPLC and Its Application to Pharmacokinetics Study,” Journal of Pharmaceutical and Biomedical Analysis, Vol. 43, No. 5, 2007, pp. 1831-1835. doi:10.1016/j.jpba.2006.12.010

[16] A. B. Ruzilawati, A. W. Mohd Suhaimi and S. H. Gan, "Genetic Polymorphisms of CYP3A4: CYP3A4*18 Allele Is Found in Five Healthy Malaysian Subjects,” Clinica Chimica Acta, Vol. 383, No. 1-2, 2007, pp. 158-162. doi:10.1016/j.cca.2007.05.004

[17] Y. D. Muthiah, W. L. Lee, L. K. Teh, C. E. Ong, M. Z. Salleh and R. Ismail, "A Simple Multiplex PCR Method for the Concurrent Detection of Three CYP2C8 Variants,” Clinica Chimica Acta, Vol. 349, No. 1-2, 2004, pp. 191-198. doi:10.1016/j.cccn.2004.06.024

[18] A. B. Ruzilawati, A. W. Mohd Suhaimi and S. H. Gan, "Population Pharmacokinetic Modeling of Repaglinide in Healthy Subjects by Using Nonparametric Adaptive Grid (NPAG) Algorithm," Journal of Clinical Pharmacy and Therapeutics, Vol. 35, No. 1, 2010, pp. 105-112. doi:10.1111/j.1365-2710.2009.01042.x

[19] B. Meibohm, I. Beierle and H. Derendorf, "How Important Are Gender Differences in Pharmacokinetics?” Clinical Pharmacokinetics, Vol. 41, No. 5, 2002, pp. 329-342. doi:10.2165/00003088-200241050-00002

[20] S. H. Haidar, S. B. Johnson, M. J. Fossler and A. S. Hussain, "Modeling the Pharmacokinetics and Pharmacodynamics of a Unique Oral Hypoglycemic Agent Using Neural Networks,” Pharmaceutical Research, Vol. 19, No. 1, 2002, pp. 87-91. doi:10.1023/A:1013611617787

[21] R. Z. Harris, L. Z. Benet and J. B. Schwartz, "Gender Effects in Pharmacokinetics and Pharmacodynamics," Drugs, Vol. 50, No. 2, 1995, pp. 222-239. doi:10.2165/00003495-199550020-00003

[22] W. R. Hutson, R. L. Roehrkasse and A. Wald, "Influence of Gender and Menopause on Gastric Emptying and Motility,” Gastroenterology, Vol. 96, No. 1, 1989, pp. 617-629.

[23] F. Abad-Santos, J. Novalbos, M. A. Galvez-Mugica, S. Gallego-Sandin, S. Almeida and F. Vallee, “Assessment of Sex Differences in Pharmacokinetics and Pharmacodynamics of Amlodipine in a Bioequivalence Study," Pharmaceutical Research, Vol. 51, No. 5, 2005, pp. 445452. doi:10.1016/j.phrs.2004.11.006

[24] F. Franconi, S. Brunelleschi, L. Steardo, et al., "Gender Differences in Drug Responses,” Pharmaceutical Research, Vol. 55, No. 2, 2007, pp. 81-95. doi:10.1016/j.phrs.2006.11.001

[25] D. J. Greenblatt, M. Divoll and D. R. Abernethy, "Physiologic Changes in Old Age: Relation to Altered Drug Disposition,” Journal of the American Geriatrics Society, Vol. 30, Supplement 11, 1982, pp. S6-S10.

[26] M. Chen, L. Ma, G. L. Drunsano and A. N. Nafziger, 
"Sex Differences in CYP3A4 Activity Using Intravenous and Oral Midazolam,” Clinical Pharmacology \& Therapeutics, Vol. 80, No. 5, 2006, pp. 531-538. doi:10.1016/j.clpt.2006.08.014

[27] D. L. Schmucker, K. W. Woodhouse, R. K. Wang, H. Wyne, O. H. James and M. McManus, "Effects of Age and Gender on in Vitro Properties of Human Liver Microsomal Mono-Oxygenase,” Clinical Pharmacology \& Therapeutics, Vol. 48, No. 4, 1990, pp. 365-374. doi:10.1038/clpt.1990.164

[28] P. He, M. H. Court, D. J. Greenblatt and L. L. von-Moltke, "Genotype-Phenotype Associations of Cytochrome P450 3A4 and 3A5 Polymorphism with Midazolam Clearance in Vivo," Clinical Pharmacology \& Therapeutics, Vol. 77, No.
5, 2005, pp. 373-387. doi:10.1016/j.clpt.2004.11.112

[29] R. Wolbold, K. Klein, O. Burk, A. K. Nussler, P. Neuhaus and M. Eichelbaum, "Sex Is a Major Determinant of CYP3A4 Expression in Human Liver,” Hepatology, Vol. 38, No. 4, 2003, pp. 978-988.

[30] E. Tanaka, "Gender-Related Differences in Pharmacokinetics and Their Clinical Significance," Journal of Clinical Pharmacy and Therapeutics, Vol. 24, No. 5, 1999, pp. 339-346. doi:10.1046/j.1365-2710.1999.00246.x

[31] K. T. Kivisto and H. K. Kroemer, "Use of Probe Drugs as Predictors of Drug Metabolism in Humans,” The Journal of Clinical Pharmacology, Vol. 37, Supplement 1, 1997, pp. 40S-48S. doi:10.1177/009127009703700121 